\title{
Preparation, characterization, and antiproliferative activities of biotin-decorated docetaxel-loaded bovine serum albumin nanoparticles
}

\author{
Kai Cheng, Shaoping Sun, Xianfeng Gong* \\ Institute of Chemistry and Materials Science, Heilongjiang University, Harbin, China
}

\begin{abstract}
The aim of the present study was to characterize biotin-decorated docetaxel-loaded bovine serum albumin nanoparticles (DTX-BIO-BSA-NPs) and evaluate their antiproliferative activity in vitro. The particle size of prepared DTX-BIO-BSA-NPs was found to be always lower than $200 \mathrm{~nm}$, with sizes of 166.9, $160.3,159.0,176.1$ and $184.8 \mathrm{~nm}$ and the zeta potential was $-29.51,-28.54,-36.54,-36.08$ and $-27.56 \mathrm{mV}$ after redissolution with water for $0,1,2,4$ and 8 hours, respectively. The polydispersity index (PDI) was stable in the range of $0.170-0.178$. In the in vitro drug-release study, the DTX-BIO-BSA-NPs targeted a human breast cancer cell line MCF-7 effectively. The X-ray diffraction spectrum and DSC curve of DTX-BIO-BSA-NPs suggested that docetaxel was in an amorphous or disordered crystalline phase in DTX-BIO-BSA-NPs. In vitro cytotoxicity results showed that DTX-BIO-BSA-NPs inhibits proliferation of MCF-7, SGC7901, LS-174T and A549 cells in a concentration-dependent manner after exposure to DTX-BIO-BSA-NPs for 48 hours. Taken together, these results indicate that DTX-BIO-BSA-NPs may have potential as an alternative delivery system for parenteral administration of docetaxel.
\end{abstract}

Keywords: Albumin/nanoparticles/characterization. Docetaxel. Antiproliferative activities. Biotin.

\section{INTRODUCTION}

Docetaxel (DTX) is a semi-synthetic, taxanederived, highly potent anticancer drug. It represents the second generation of taxane anticancer drugs and has shown broad spectrum antitumor activity against prostate, breast, pancreatic, lung, gastric and hepatic carcinomas (Xu et al., 2009; Hwang, 2012; Zhao, Astruc, 2012; Chen et al., 2016). Docetaxel binds irreversibly with $\beta$-actin and stabilizes the microtubule assembly which is responsible for inhibition of cell division and finally cell death (Musumeci et al., 2006). Therefore this drug is currently used as a first-line treatment in clinical chemotherapy. However, the current preparations of docetaxel have some drawbacks such as water-insolubility, sensitization and toxic side effects.

Nanoparticles are made of a variety of polymers, such as polysaccharides (Fernandez-Urrusuno et al., 1999; Liu et al., 2008), proteins (Elzoghby, 2013; Harsha 2013)

\footnotetext{
*Correspondence: X. Gong. Institute of Chemistry and Materials Science, Heilongjiang University, 150000 - 74 Xuefu Road - Harbin, PR China. E-mail: gongxianfeng@hlju.edu.cn / gongxianfeng@sina.com
}

and synthetic polymers (Fattal et al., 1998; Breunig, Bauer, Goepferich, 2008). Among all the available materials, biological molecules have attracted considerable interest for application to nanomedicine because they are fully biocompatible and water-soluble (Kratz, 2008). Biological molecules have several advantages over small molecules and polymers for biomedical applications. First, the watersolubility of surface-modified nanoparticles generally increases with increasing mass of the ligands (Ackerson, Jadzinsky, Kornberg, 2005; Sperling, Parak, 2010) and thus, biological molecules will provide enhanced water-solubility for nanoparticles. Second, conjugating biological molecules to nanoparticles controls the release of drug in a sustained manner over a longer period of time (Roney et al., 2005).

As a water-soluble protein, serum albumin is the most abundant and basic protein of blood plasma. It is primarily involved in the transport of substances in the blood that are poorly soluble in water, including drugs, and also alters the disposition of endogenous and exogenous compounds present in blood (Moreno, Cortijo, Gonzalez-Jimenez, 1999). Albumin is also reported to associate with nanoscale particles to promote 
their transportation through cells (Mehta et al., 2004; Zhang et al., 2008). Additionally, albumin nanoparticles exhibited high binding capacity of various drugs (Jithan et al., 2011; Kratz, 2014) and were well tolerated without any serious side effects (Ibrahim et al., 2002). Bovine serum albumin (BSA) is an important carrier protein in blood plasma for several ions and molecules. It is one of the most extensively-studied proteins and has structural homology to human serum albumin as a substitute for research (Yu et al., 2012). Accordingly, albumin nanoparticles have received considerable attention (Elzoghby, Samy, Elgindy, 2012). Encouragingly, a paclitaxel-loaded human serum albumin nanoparticles (Abraxane) was approved by FDA for clinical use in 2005. It improved water solubility of paclitaxel with enhanced efficacy and tolerability compared with a Cremophor-based paclitaxel formulation (Cortes, Saura, 2010). Targeted therapy is among the most attractive strategies for cancer, the major cause of death in most advanced countries in the world. Conventional cancer chemotherapy, which usually utilizes small molecule drugs, is far from successful, mostly due to the lack of tumor selectivity, which leads to dose-limiting toxicity, resulting severe adverse effects that limits usage. To overcome these drawbacks, targeted anticancer therapy is aims to have tumor-selective anticancer effects with less systemic side effects. To increase the delivery of a given drug to a specific target site, albumin can be surface conjugated using various targeting moieties or ligands, such as folate, saccharide, biotin and peptides. Among them, biotin is used widely as a tumor targeting ligand for various anti-cancer drugs.

Biotin (vitamin $\mathrm{H}$ ) participates as a coenzyme in reactions involving $\mathrm{CO}_{2}$ such as carboxylations, transcarboxylations, and decarboxylations. Biotin is widely applied in two-step pretargeting strategies (Balthasar et al., 2005; Mårtensson et al., 2007; Lesch et al., 2010; Lindegren, Frost, 2011; Uppal et al., 2011; Marysael et al., 2012; Urbanska et al., 2012). Recent studies revealed that biotin receptors were over-expressed on numerous tumors characterized by rapid dividing and aggressive growth (Russell-Jones et al., 2004; Patel et al., 2012; Li et al., 2013).

In this paper, we introduced biotin ligand on the surface of docetaxel-loaded bovine serum albumin nanoparticles (DTX-BIO-BSA-NPs) in an attempt to specifically target the corresponding receptors of carcinoma. This study aimed to formulate DTX-BIOBSA-NPs and evaluate their physicochemical properties, measure in vitro release and determine their effectiveness in tumor cells.

\section{MATERIAL AND METHODS}

\section{Material}

Bovine serum albumin was provided by Instituto Grifols, S.A. (Barcelona, Spain). The docetaxel was obtained from Shanghai Kairen Bio-Technology Co. Ltd (Shanghai, China). Fetal calf serum was obtained from Shanghai Solarbio Biosience and techolgo Co. Ltd (Shanghai, China). Phosphate-buffered saline (pH7.4) and trypsin were purchased from Sigma Chemicals Co. (St. Louis, USA). Fluorescein isothiocyanate (FITC) and LysoTracker Red were purchased from Beyotime Institute of Biotechnology (Haimen, China). RPMI 1640 medium was obtained from HyClone Inc. (Logan, USA). Acetonitrile and methanol (HPLC-grade) were obtained from J\&K Chemical Ltd (Beijing, China). Water was collected from a Milli-Q organic free water system (Millipore, Bedford, USA). All the other chemical agents and chemicals were used as analytic reagents.

\section{Preparation of DTX-BIO-BSA-NPs}

The DTX-BIO-BSA-NPs were prepared as previously described using a desolvation technique (Jun et al., 2011). Briefly, $75 \mathrm{mg}$ bovine serum albumin was first dissolved in $7.5 \mathrm{~mL}$ deionized water, then 33.75 $\mathrm{mg}$ docetaxel dissolved in $22.5 \mathrm{~mL}$ ethanol was added using a peristaltic pump BT01-100 (Kejian, Changzhou, China) at room temperature $(1 \mathrm{~mL} / \mathrm{min})$. Afterwards, $220 \mu \mathrm{L}$ of $0.25 \%(\mathrm{v} / \mathrm{v})$ glutaraldehyde was added to the resultant solution for amino groups crosslink in the nanoparticles. The cross-linking process was performed during stirring of the suspension for $15 \mathrm{~h}$. The organic reagents were removed by evaporation using a rotary evaporator RE-52AA (Yarong, Shanghai, China) at $45^{\circ} \mathrm{C}$, and the nanoparticles were then redispersed in an ultrasonication bath FRQ-1008T (Front, Hangzhou, China). The nanoparticles were collected by centrifugation at $10000 \mathrm{~g}$ for $10 \mathrm{~min}$ (Sigma, Harz, Germany), followed by washing twice with ethanol and deionized water. N-hydroxysuccinimide ester of biotin (NHS-biotin) was prepared according with the method described by $\mathrm{Xu}$ et al. (2007). NHS-biotin $5 \mathrm{mg}$ was dissolved in $0.1 \mathrm{M}$ carbonate/bicarbonate buffer $(\mathrm{pH} 9.0,1.0 \mathrm{~mL})$ and the stirred DTX-BSA-NPs suspension was added. It took $16 \mathrm{~h}$ for reaction. The carboxylic groups of NHS-biotin were conjugated with the amino groups of the BSA-NPs under alkaline conditions. With centrifuged at $8000 \mathrm{~g}$ for 10 min twice, the unassociated NHS-biotin in the mixture was then removed. Followed by freeze-drying (Scientz- 
$10 \mathrm{~N}$, NingBo, China) under a condition of controlled temperature $\left(-40^{\circ} \mathrm{C}\right.$ for $24 \mathrm{~h}$ followed by $-70{ }^{\circ} \mathrm{C}$ for $\left.72 \mathrm{~h}\right)$ and pressure (1 pa) using 5\% mannitol as a freeze-drying agent, the DTX-BIO-BSA-NPs were obtained.

\section{Morphology, particle size, and zeta potential of the DTX-BIO-BSA-NPs}

A suitable amount of the lyophilized sample was dispersed in water. A drop of the solution was dropped on a round coverslip then blow-dried with sterile wind using a sterile bench, which also prevented dust from affecting the drop. The coverslip coated with the sample was used to investigate the morphology by SEM (FEI Co., Eindhoven, The Netherlands).

DTX-BIO-BSA-NPs were dispersed in water to attain a concentration of $5 \mathrm{mg} / \mathrm{mL}$. Then $3 \mathrm{~mL}$ of the solution was placed in a sample cell to detect the particle size by laser light scattering and the zeta potential using a ZetaPlus Zeta Potential Analyzer (Brookhaven Instruments, Holtsville, USA). The data were obtained from the average of three measurements.

\section{Physical status of docetaxel and DTX-BIO-BSA- NPs}

An x-ray diffractometer (Philips, The Netherlands) was used to determine the physical status of docetaxel in the nanoparticles. The diffraction angle $(2 \theta)$ was recorded from $3^{\circ}$ to $80^{\circ}$ with a scanning speed of $5^{\circ} /$ minute. CuKa radiation was used as the $\mathrm{x}$-ray source at $40 \mathrm{kV}$ and $30 \mathrm{~mA}$.

\section{Differential scanning calorimetry (DSC)}

Differential scanning calorimetry is a thermoanalytical technique in which the difference in the amount of heat required to increase the temperature of a sample and reference is measured as a function of temperature. In this paper, Five milligrams of samples were sealed in the aluminum pan and investigated by differential scanning calorimeter (TA instruments, Wilmington, USA) at a temperature heating rate of $10{ }^{\circ} \mathrm{C} / \mathrm{min}$ that from 35 to $350{ }^{\circ} \mathrm{C}$ with nitrogen at a flow rate of $100 \mathrm{~mL} / \mathrm{min}$ and pressure of 40 bar. The DSC was calibrated with indium, with an empty pan used as reference.

\section{Docetaxel determination by high-performance liquid chromatography}

The docetaxel in ethanol was examined by highperformance liquid chromatography, i.e. a Waters liquid chromatograph (Waters Corporation, Milford, USA), consisting of a Waters 600 Controller equipped with a Waters 717 Plus autosampler and a Waters 2487 UV detector. The samples were chromatographed at $25^{\circ} \mathrm{C}$ by injection of a $20 \mu \mathrm{L}$ sample into a Hypersi C18 column $(250 \mathrm{~mm} \times 4.6 \mathrm{~mm} \times 5 \mu \mathrm{m}$, DEAIC Company, Dalian, China). The mobile phase was a mixture of deionized water and acetonitrile in a volume ratio of 53:47 (v/v). The elution rate was $1.0 \mathrm{~mL} / \mathrm{min}$ and the wavelength was set at $231 \mathrm{~nm}$.

\section{Drug release}

Drug release from DTX-BIO-BSA-NPs was studied and compared with drug release/diffusion from DTX suspension using a dialysis bag method (Liu et al., 2011). The phosphate-buffered saline (0.1 M, pH 7.4) at $37{ }^{\circ} \mathrm{C}$ was used to determine the docetaxel release from the nanoparticles. After adding DTX-BIO-BSANPs suspension $(0.5 \mathrm{mg} / \mathrm{mL}, 2 \mathrm{~mL}$, without trehalose $)$ or docetaxel solution $(0.05 \mathrm{mg} / \mathrm{mL}, 2 \mathrm{~mL})$ into SlideA-Lyzer dialysis cassettes (Sigma-Aldrich, St. Louis, USA), the dialysis cassettes were then immersed in a $250 \mathrm{~mL}$ beaker containing $200 \mathrm{~mL}$ release buffer, which was placed in an incubator shaker (Jiangsu Jintan Medical Instruments Co., Ltd., Jintan, China) at $37^{\circ} \mathrm{C}$ and $120 \mathrm{rpm}$. Later, with drawn from the beaker, $50 \mathrm{~mL}$ release buffer was replaced with $50 \mathrm{~mL}$ fresh release buffer by regular intervals. Each collected release buffer sample was concentrated to $1 \mathrm{~mL}$ by rotary evaporator, docetaxel was resolved by high-performance liquid chromatography and extracted from the removed medium after dividing into the organic phase. After being added to the medium, $5 \mathrm{~mL}$ chloroform was fully vortexed for 5 min and allowed to stand for 15 min for phase separation. Upon phase separation, the denser organic chloroform layer was carefully partitioned from the aqueous buffer phase and permitted to evaporate at the indoor temperature overnight. The dried sample containing docetaxel was then dissolved in $4 \mathrm{~mL}$ of methanol and analyzed by high-performance liquid chromatography. It was plotted to a profile showing cumulative drug release on the basis of time. And each diffusion experiment was operated repeatedly in triplicate, the average values and normal deviations were calculated in detail.

\section{In vitro cellular uptake}

Human breast cancer cell line MCF-7 were used for studying the in vitro cellular uptake of the DTX-BSANPs and DTX-BIO-BSA-NPs labeled with fluorescein 
isothiocyanate (FITC) and Lyso-Tracker Red. MCF-7 cells were plated in 6-well transparent plates of 300, 000 cells per well, and incubated for 24 hours before labeling with FITC and Lyso-Tracker Red. After labeling with FITC and Lyso-Tracker Red for 2 hours at $37^{\circ} \mathrm{C}$, the cells were observed by confocal laser scanning microscopy (Nikon, Tokyo, Japan) with fluorescence view imaging software.

\section{Cytotoxic activities}

To evaluate the cytotoxicity of DTX-BIO-BSANPs and free docetaxel, MTT assay was used to test five different concentrations (1.25 nM, $12.5 \mathrm{nM}, 125 \mathrm{nM}$, $1.25 \mu \mathrm{M}$ and $12.5 \mu \mathrm{M}$ ) of DTX-BIO-BSA-NPs and docetaxel against MCF-7 cells, SGC7901 cells, LS$174 \mathrm{~T}$ cells and A549 cells at $48 \mathrm{~h}$, and compared the cytotoxicity between the DTX-BIO-BSA-NPs and free docetaxel. MCF-7 (Human breast cancer cell line), SGC7901 (human gastric carcinoma cell line), LS-174T (human colon adenocarcinoma cell line) and A549 (human lung adenocarcinoma cell) were obtained from the Harbin Tumor Institute (Harbin, Heilongjiang, China). All cells were cultured in RPMI 1640 containing $10 \%$ fetal bovine serum, $100 \mathrm{U} / \mathrm{mL}$ penicillin and $100 \mu \mathrm{g} /$ $\mathrm{mL}$ streptomycin at $37{ }^{\circ} \mathrm{C}$ in a humidified $5 \% \mathrm{CO}_{2}$ incubator. Cells $(50,000$ per well) were seeded in 96well tissue culture plates for $12 \mathrm{~h}$ and were then treated with the DTX-BIO-BSA-NPs of different concentration or docetaxel control solution for $48 \mathrm{~h}$. The media were then removed and cells were washed with PBS. An MTT assay was performed by adding $10 \mu \mathrm{L}$ MTT reagent $(5 \mathrm{mg} / \mathrm{mL})$ to each well and cells were then incubated for $4 \mathrm{~h}$, after which culture media were replaced with $150 \mu \mathrm{L}$ of DMSO. Light absorbance of the solution was measured at $492 \mathrm{~nm}$ using a multi-plate reader (Awareness Technologies, Palm City, USA). The cell inhibitory rate was calculated as follows: inhibition rate $=\left[\left(\mathrm{Abs}_{492 \text { control cells }}-\mathrm{Abs}_{492 \text { treated cells }}\right) / \mathrm{Abs}_{492 \text { control cells }}\right] \times 100 \%$. All assays were done with six parallel replicates. Cell viability at different concentrations of compounds was plotted and $50 \%$ inhibition of growth was calculated as $\mathrm{IC}_{50}$.

\section{Statistical analysis of the data}

Data are presented as the mean \pm standard deviation for all treatments. Student's t-test was used to evaluate the significance of differences between the treated and control groups. A value of $\mathrm{p}<0.05$ was considered significant.

\section{RESULTS AND DISSCUSSION}

\section{Morphology, particle size and zeta-potential of DTX-BIO-BSA-NPs}

Particle size is an important aspect for the passive targeting of nanoparticles (Stylianopoulos, 2013). Scanning electron microscopy (SEM) studies were carried out to determine the size and shape of nanoparticle, the images of which are shown in Figure 1. Raw docetaxel presented as irregular blocks, with a particle size ranging from 1 to $10 \mu \mathrm{m}$ (Figure 1A). DTX-BSA-NPs and DTX-BIO-BSA-NPs exhibit a nearly spherical shape dispersed evenly (Figure 1B and 1C), consistent with the report of Zhu et al. (2016). The freeze-dried powder and aqueous dispersion of the powder are shown in Figure 1D. This image demonstrates that the freeze-dried powder reconstitutes well in solution, with a transparent opalescence and uniform state observable.

The dispersion of DTX-BIO-BSA-NPs in water was studied to measure the stability of the solution after 8 hours at a temperature of $25^{\circ} \mathrm{C}$. The particle size was always lower than $200 \mathrm{~nm}$ after redissolution with water during studied times as presented in Table I. DTX-BIO-BSANPs are small enough for the particles to accumulate in tumor tissue selectively via the enhanced permeation and retention effect (Nichols, Bae, 2014; Araki et al., 2015). Restricting the size of nanoparticles to a range between 100-200 nm enhances extravasation from tumor blood microvessels as well as interstitial transport, leading to the accumulation and retention of nanoparticles in solid tumors (Vardhan et al., 2017).

Zeta potential is defined as the difference of electrical potential between the surface of the cells and the bulk-surrounding medium. The surface charge has important effect on the stability of nanoparticles in solution (Ye et al., 2016). In our experiments, the zeta potentials were $-29.51,-28.54,-36.54,-36.08$ and $-27.56 \mathrm{mV}$ for $0,1,2,4$ and 8 hours, respectively (Table I), and the polydispersity index (PDI) was stable in the range between $0.170-0.178$. The phenomena of particle reunion, precipitation, and stratification did not occur when the solution was stored after 8 hours and the dispersion appeared equally distributed. Lower PDI indicated good dispersibility, a prerequisite of good stability. Higher zeta potential supported that the DTX-BIO-BSA-NPs did not aggregate much in the aqueous state in general and physiologically-relevant media in particular. Therefore, the DTX-BIO-BSA-NPs dispersion demonstrated good stability over the 8-hour observation period.

The x-ray diffraction spectrum of docetaxel and 

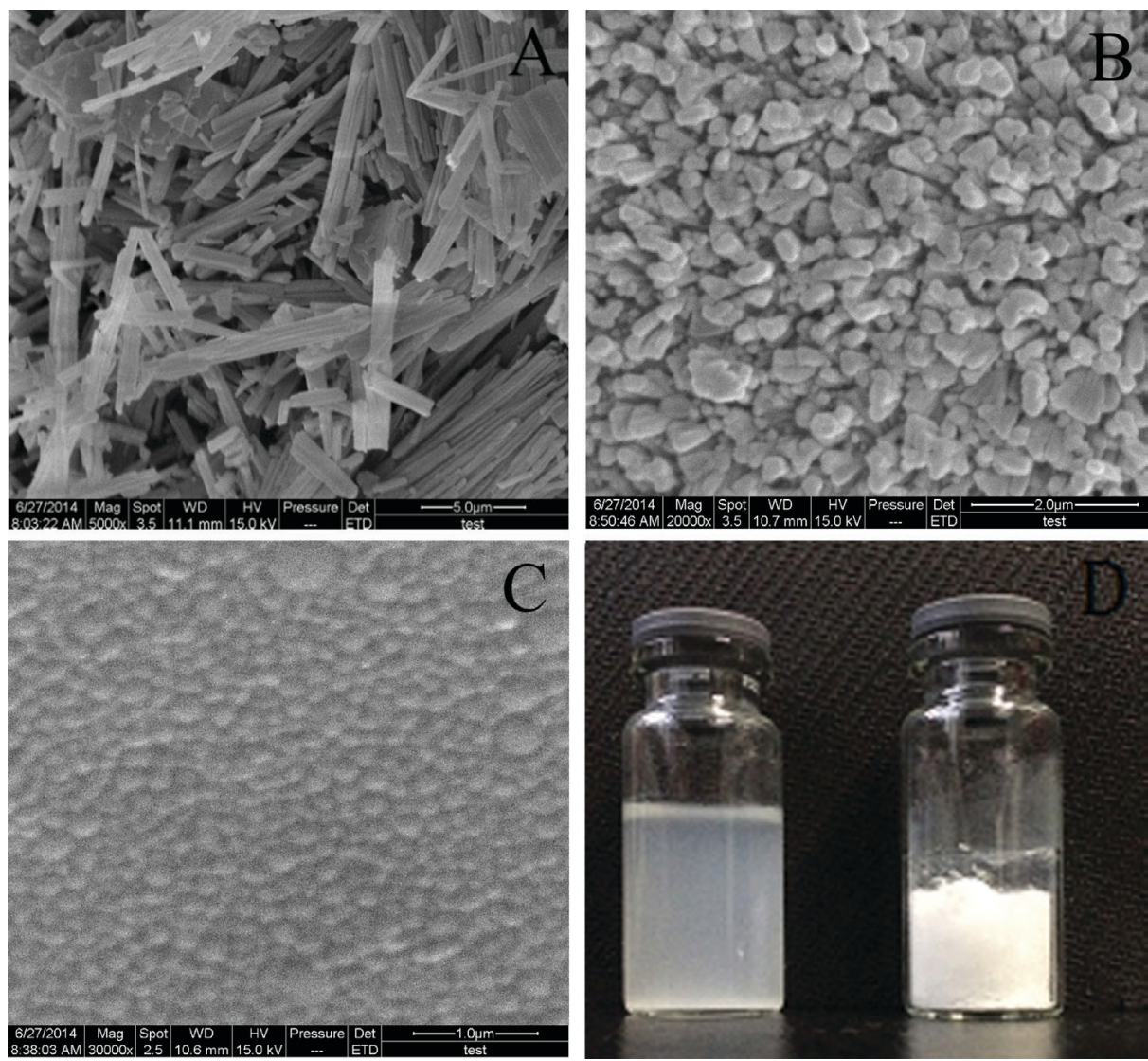

FIGURE 1 - Characterization of DTX, DTX-BSA-NPs and DTX-BIO-BSA-NPs. Scanning electron microscopic images of (A) raw docetaxel (magnification: 5000×). (B) DTX-BSA-NPs (magnification: 20000×). (C) DTX-BIO-BSA-NPs (magnification: 30000×). (D) Reconstitution appearance of DTX-BIO-BSA-NPs solution (left) and freeze-dried DTX-BIO-BSA-NPs powder (right).

freeze-dried DTX-BIO-BSA-NPs is shown in Figure 2. The disappearance of the characteristic peak $\left(2 \theta=7.84^{\circ}\right.$, $12.36^{\circ}, 16.58^{\circ}$ ) of docetaxel in the DTX-BIO-BSANPs suggested that docetaxel was in an amorphous or disordered crystalline phase in the solid solution state. In addition, the DSC curves of samples (Figure 3 ) showed there is a peak at $222{ }^{\circ} \mathrm{C}$ in the docetaxel curve which stands for docetaxel melting point peak in its crystalline form. This peak is not observed in DTX-BIO-BSA-NPs, which further demonstrated that docetaxel was in an amorphous or disordered crystalline state. (Musumeci et al., 2006; Yallapu et al., 2010).

\section{In vitro drug release}

In vitro drug release studies are crucial to mimic the release of drug in a physiological environment. In vitro release of docetaxel from pure drug suspension and DTXBIO-BSA-NPs were performed in PBS ( $\mathrm{pH}$ 7.4). Among the experimental methods available for determining the in vitro release pattern of docetaxel from docetaxel suspension and DTX-BIO-BSA-NPs, the dialysis bag method is the most suitable. The dialysis bag retains the nanoparticles and allows the diffusion of free drug into release media, where samples were withdrawn from and analysed (Zuo et al.,

TABLE I - Particle size, zeta potential and polydispersity index changes of DTX-BIO-BSA-NPs over 8 hours

\begin{tabular}{cccc}
\hline $\begin{array}{c}\text { Redissolution } \\
\text { time }(\mathbf{h})\end{array}$ & $\begin{array}{c}\text { Mean diameter } \pm \text { SD } \\
(\mathbf{n m})\end{array}$ & $\begin{array}{c}\text { Zeta potential } \\
(\mathbf{m V})\end{array}$ & Polydispersity \\
\hline 0 & $166.9 \pm 23.8$ & $-29.51 \pm 1.66$ & $0.170 \pm 0.016$ \\
1 & $160.3 \pm 25.6$ & $-28.54 \pm 1.93$ & $0.176 \pm 0.012$ \\
2 & $159.0 \pm 21.4$ & $-36.54 \pm 1.77$ & $0.178 \pm 0.010$ \\
4 & $176.1 \pm 23.0$ & $-36.08 \pm 0.87$ & $0.177 \pm 0.010$ \\
8 & $184.8 \pm 24.2$ & $-27.56 \pm 1.79$ & $0.171 \pm 0.010$ \\
\hline
\end{tabular}




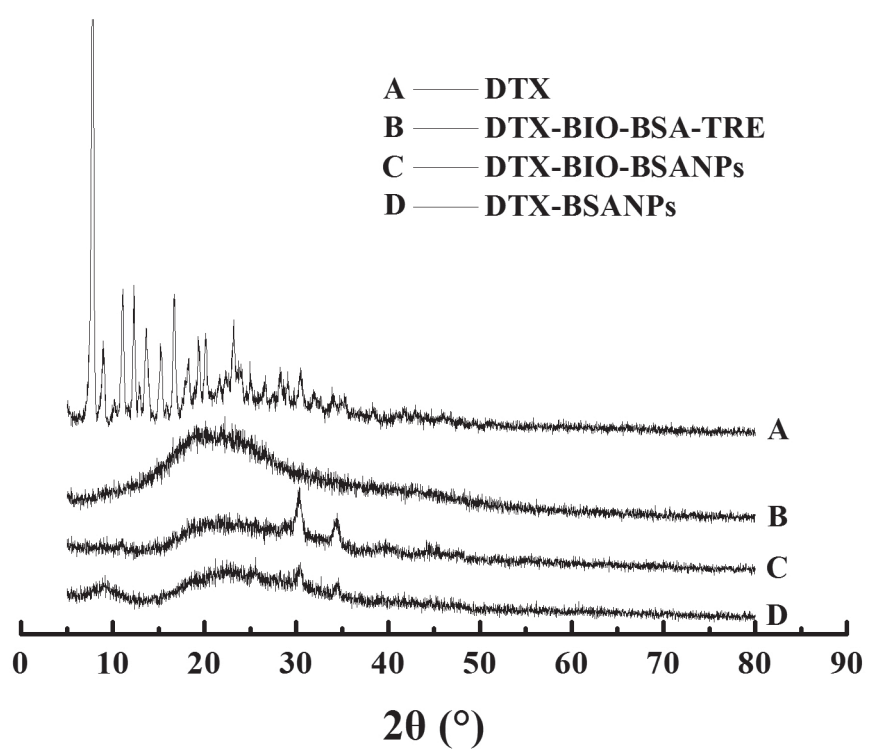

FIGURE 2 - The X-ray diffraction spectrum of docetaxel and freeze-dried DTX-BIO-BSA-NPs. A, docetaxel; B, docetaxelloaded biodegradable bovine serum albumin nanoparticles with biotin decoration and trehalose. C, docetaxel-loaded biodegradable bovine serum albumin nanoparticles with biotin decoration; D, docetaxel-loaded biodegradable bovine serum albumin nanoparticles.

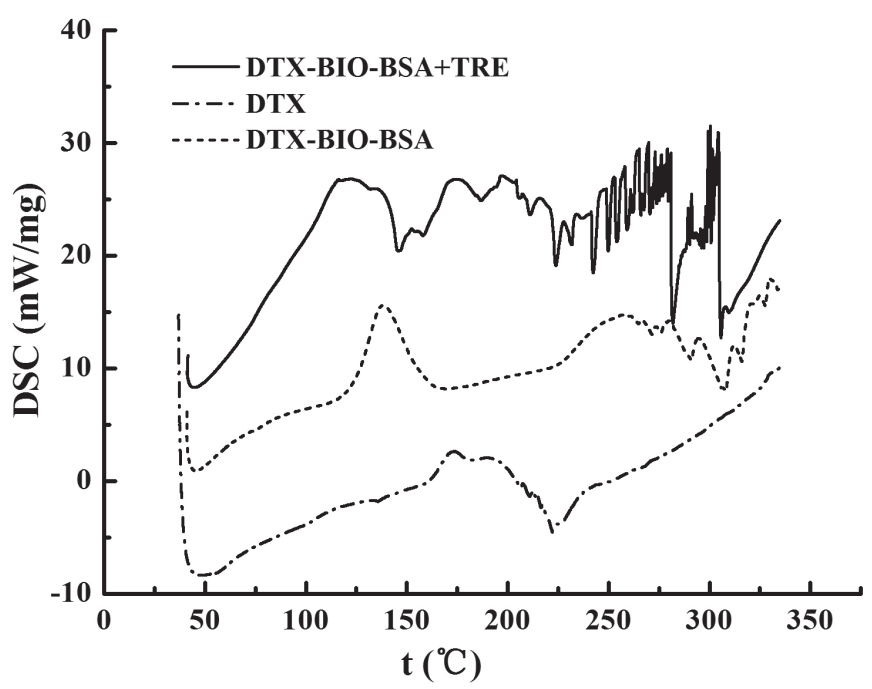

FIGURE 3 - The differential scanning calorimetry of docetaxel and freeze-dried DTX-BIO-BSA-NPs. DTX, docetaxel; DTX-BIO-BSA, docetaxel-loaded biodegradable bovine serum albumin nanoparticles with biotin decoration; DTXBSA-BIO+trehalose (TRE), docetaxel-loaded biodegradable bovine serum albumin nanoparticles with biotin decoration and trehalose.

2016). The in vitro drug release profiles were represented as a cumulative percentage of drug released with respect to time. The in vitro drug release profiles of the DTX-BIOBSA-NPs in PBS (pH7.4) in the first 4 days are illustrated in Figure 4. The docetaxel release from the DTX-BIOBSA-NPs is a complex process, which could be attributed to docetaxel diffusion in the bovine serum albumin carrier followed by BSA degradation. As shown in Figure 4, the free drug was found to release completely within 12 hours, reflecting the diffusion profile of free drug through the dialysis membrane. Similar results were reported by Liu and co-workers (Liu et al., 2016). In comparison, the drug release from DTX-BIO-BSA-NPs presented sustained release pattern which demonstrated the potential for prolonging therapeutic exposure time. For example, an initial slow release from DTX-BIO-BSA-NPs of $29.1 \%$ in the first 8 hours can be observed. In the following 28 hours, burst release increased release to $59.0 \%$, in a sustained manner, which provides the possibility to continuously fight against cancer cells, resulting in decreased cancer cell viability. The cumulative release of DTX-BIO-BSA-NPs $(81.6 \%)$ was less than that of docetaxel $(89.9 \%)$ after 4 days, attributed to the docetaxel being well encapsulated in the rigid core of DTX-BIO-BSA-NPs. A cumulative release of $81.6 \%$ after 4 days shows that the nanoparticle formulation reaches almost full release of docetaxel. The generally sustained and controlled release profile of docetaxel facilitates the application of nanoparticles for the delivery of anticancer drugs (Gan, Chien, Feng, 2010).

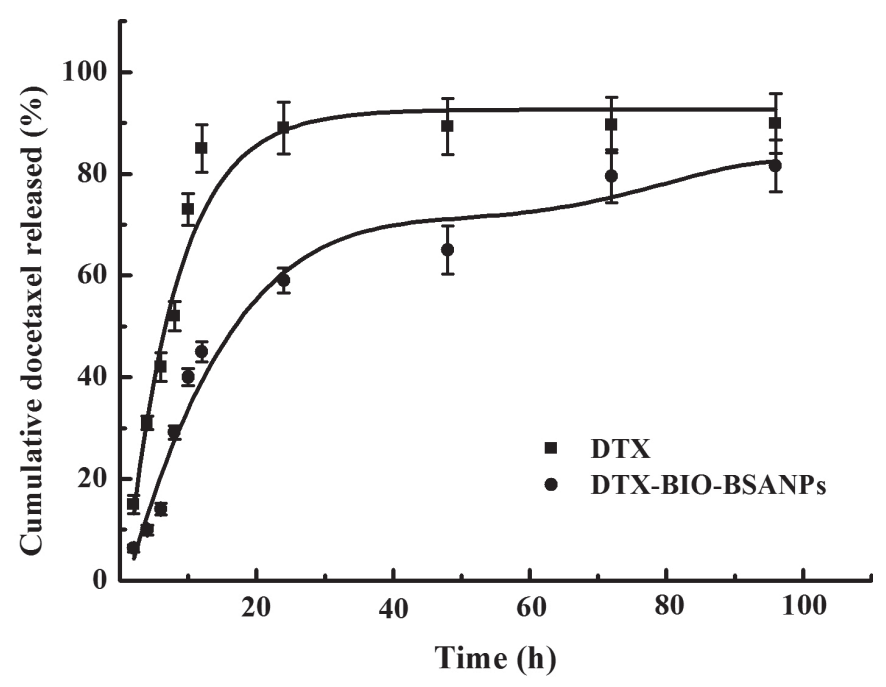

FIGURE 4 - In vitro docetaxel release profile from DTX-BIOBSA-NPs and docetaxel (Taxoere ${ }^{\mathrm{TM}}$ ). Phosphate-buffered saline $(0.1 \mathrm{M}, \mathrm{pH}=7.4)$ was selected as the release medium. The nanoparticle dispersion was put in an orbital shaker and shaken at $120 \mathrm{rpm}$ at $37^{\circ} \mathrm{C}$. High-performance liquid chromatography was performed to measure the released drug concentration.

\section{In vitro cellular uptake}

The therapeutic effects of the drug-loaded 
nanoparticles would depend on internalization and sustained retention of the nanoparticles by the diseased cells. The in vitro research could provide some preliminary evidence to display the advantages of the nanoparticle formulation in comparison with the free drug. The cellular uptake of DTX-BSA-NPs and DTX-BIO-BSANPs labeled by fluorescein isothiocyanate (a fluorescent probe) was examined to demonstrate internalization of the nanoparticles into cells and the targeting effects. Internalization of the DTX-BIO-BSA-NPs was visualized by confocal laser scanning microscopy. In Figure 5 (AC), the fluorescence from the nanoparticles internalized in cells is shown. Figure 5 (B and C) shows the images of the cells incubated for $4 \mathrm{~h}$ with DTX-BSA-NPs and DTX-BIO-BSA-NPs. A significant fluorescence difference between DTX-BSA-NPs and DTX-BIO-BSA-NPs can be observed. The results show that the biotin-conjugated nanoparticles (DTX-BIO-BSA-NPs) had better target delivery than nanoparticles without biotin conjugation (DTX-BSA-NPs). High-affinity biotin-binding protein was characterized in human breast cancer cell line MCF7 , and biotin-avidin binds to the membrane fraction that cross reacts with the anti-intestines-specific membrane antigen antibody. The results of Nateghian et al. (2016) demonstrated that biotin-decorated docetaxel-loaded human serum albumin conjugates were more powerful in the reduction in tumor size and increased the survival rate when compared to free docetaxel. Therefore, we firmly believe that the DTX-BIO-BSA-NPs with smaller hydrodynamic size would have higher cellular uptake efficiency.

\section{Antiproliferative efficacy of DTX-BIO-BSA-NPs against MCF-7 cells, SGC7901 cells, LS-174T cells and A549 cells in vitro}

As shown in Figure 6, the antiproliferative effect of both DTX-BIO-BSA-NPs and free docetaxel against all tested cells were no more than $15 \%$ at $12.5 \mathrm{~nm}$ concentration, and about $80 \%$ at $1.25 \mu \mathrm{m}$ concentration, indicating that both cytotoxicity profiles were similar. The drug concentration at which $50 \%$ of cells have been killed, $\mathrm{IC}_{50}$ values, of docetaxel and DTX-BIO-BSA-NPs was respectively, $0.43 \pm 0.04 \mu \mathrm{M}$ and $0.26 \pm 0.07 \mu \mathrm{M}$ for MCF-7 cells $(\mathrm{p}<0.05$, docetaxel vs. DTX-BIO-BSANPs), $0.46 \pm 0.04 \mu \mathrm{M}$ and $0.23 \pm 0.06 \mu \mathrm{M}$ for SGC7901 cells $(\mathrm{p}<0.01), 0.34 \pm 0.04 \mu \mathrm{M}$ and $0.21 \pm 0.04 \mu \mathrm{M}$ for LS-174T cells $(\mathrm{p}<0.05)$, and $0.42 \pm 0.04 \mu \mathrm{M}$ and $0.27 \pm$ $0.03 \mu \mathrm{M}$ for A549 cells $(\mathrm{p}<0.01)$. Consistent with Mirzaie et al. (2016), the cytotoxicity of DTX-BIO-BSA-NPs was significant higher that of docetaxel. Overall, the results clearly demonstrate that DTX-BIO-BSA-NPs are more effective against cancer cells than free docetaxel. The higher cytotoxicity of DTX-BIO-BSA-NPs can be attributed to synergistic combination of different mechanisms. DTXBIO-BSA-NPs were adsorbed onto the cell surface leading to an increase in drug concentration near the cell membrane, thus generating a concentration gradient that promotes the drug influx into the cell (Fonseca, Simoes, Gaspar, 2002). Cancerous cells exhibit enhanced endocytic activity and internalize the polymeric nanoparticles in the interior of the cell leading to an increase in drug concentration. In addition, free DTX molecules, are transported out by P-glycoprotein
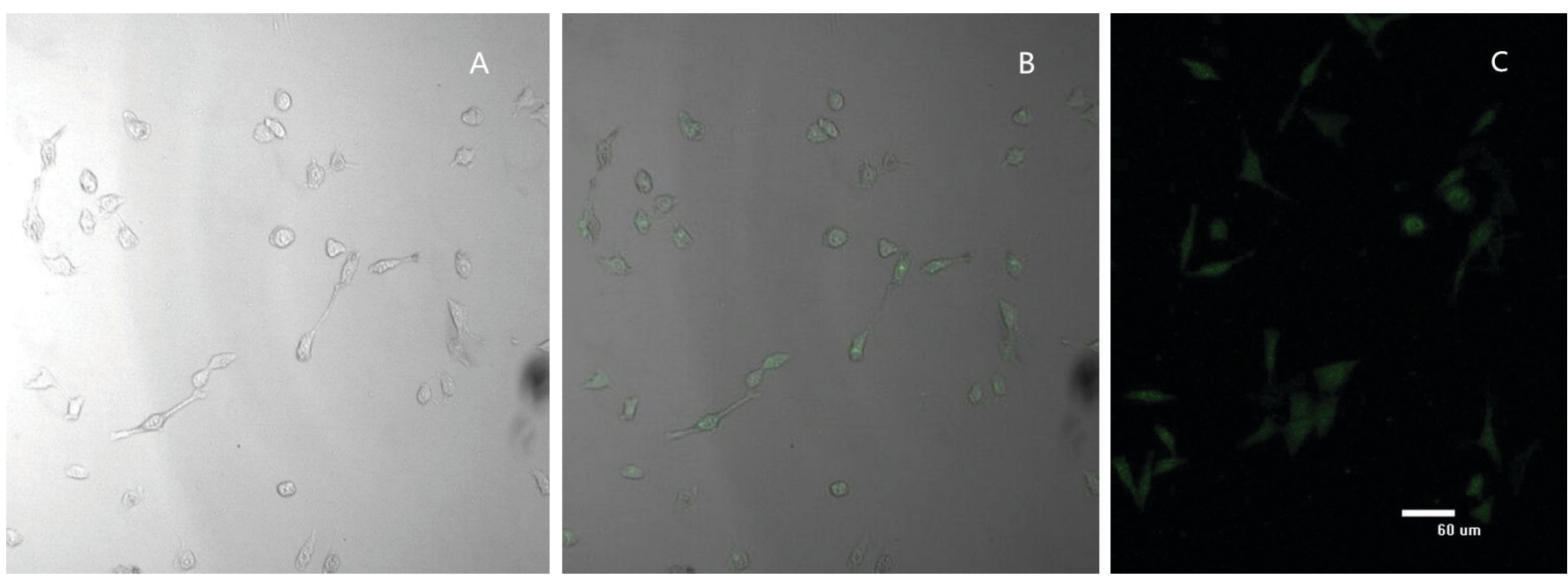

FIGURE 5 - Confocal laser scanning microcopy images show the internalization of fluorescent nanoparticles in cells. (A) MCF-7 cells with no drug incubation. (B) MCF-7 cells incubated with DTX-BSA-NPs for 2 h. (C) MCF-7 incubated with DTX-BIOBSA-NPs for $2 \mathrm{~h}$. DTX-BIO-BSANP, docetaxel-loaded biodegradable bovine serum albumin nanoparticles with biotin decoration; DTX-BSA-NPs, docetaxel-loaded biodegradable bovine serum albumin nanoparticles. 

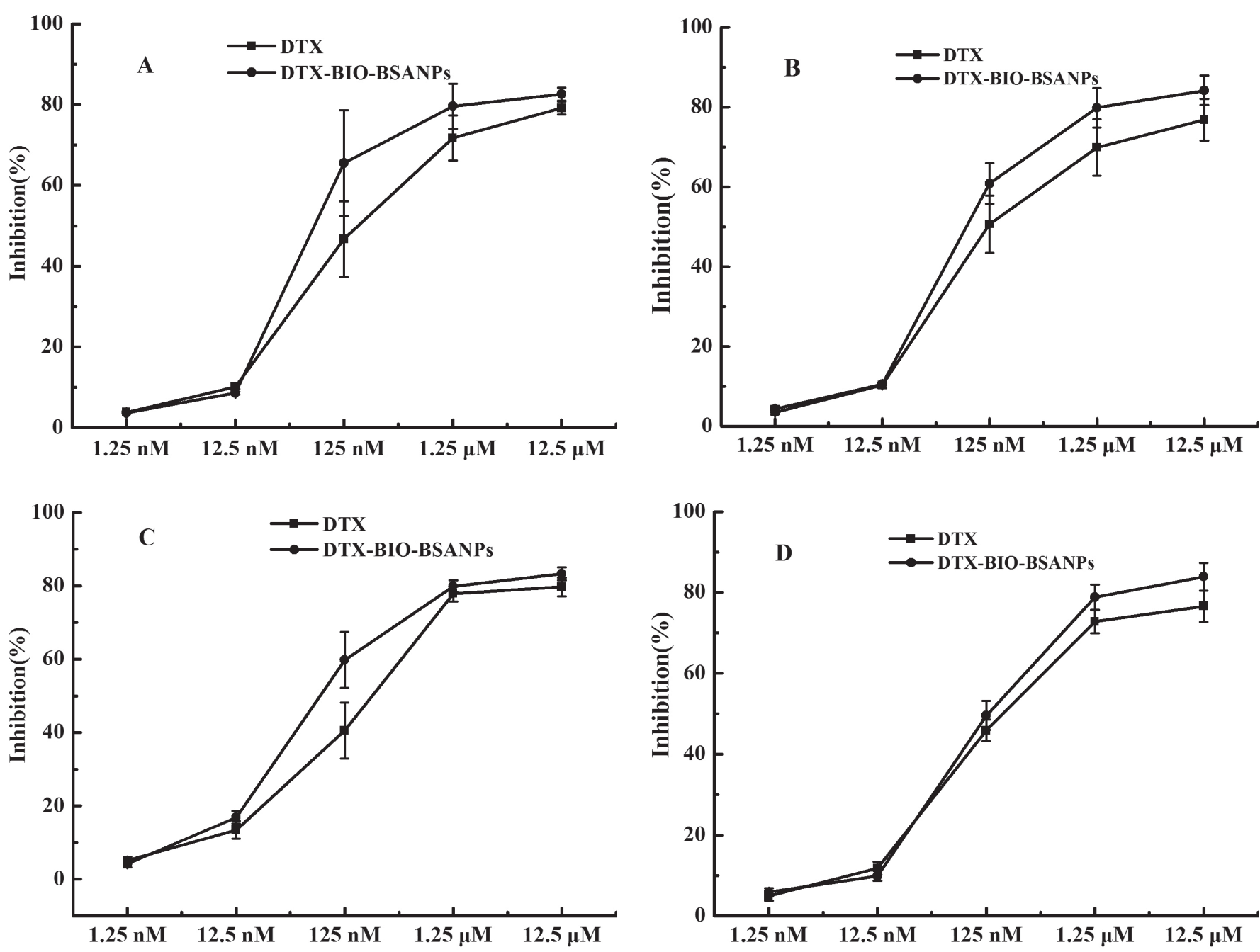

FIGURE 6 - DTX-BIO-BSA-NPs and docetaxel induces growth inhibition. The MCF-7 (A), SGC7901 cells (B), LS-174T cells (C) and A549 cells (D) were exposed to DTX-BIO-BSA-NPs $(\bullet)$ and docetaxel $(\boldsymbol{\bullet})$ at concentrations ranging from $1.25 \mathrm{nM}-12.5 \mu \mathrm{M}$ and incubated for $48 \mathrm{~h}$. The inhibitory ratio was measured by MTT assay. Data are represented as means $\pm \mathrm{SD}$ of three independent experiments with six replicates each.

(P-gp) pumps while drug-loaded nanoparticles are taken up by cells through an endocytosis pathway. Thus, it results in a higher cellular uptake of the entrapped drug, thereby enabling them to escape the effect of P-gp pumps (Panyam, Labhasetwar, 2003).

As a nanoparticle formulations are expected to reduce the side effects caused by docetaxel and improve its cellular uptake, the docetaxel-loaded nanoparticles DTXBIO-BSA-NPs could be an ideal anticancer medicine for the targeted therapy.

\section{CONCLUSION}

In this study, nanoparticles of biotin-conjugated water-insoluble docetaxel-loaded bovine serum albumin have been successfully synthesized and characterized.
The nanoparticles showed appropriate particle size, desired surface properties, high stability in favor of cellular uptake, and can be targeted specifically to cancer cells. DTX-BIO-BSA-NPs also exhibited enhanced antiproliferative effect in comparison to free docetaxel against tumor cells. The results of this study bolsters the validity of a novel DTX-BIO-BSA-NPs formulation prepared by desolvation technique using bovine serum albumin as carrier for cancer therapy, and represents a promising approach for nanoparticulate delivery systems for cytostatic agent delivery.

\section{ACKNOWLEDGEMENTS}

This work was funded by the National Natural Science Foundation of China (No. 51403057), the 
Heilongjiang Returned Overseas Fund (No. LC2013C24), the General Financial Grant from the China Postdoctoral Science Foundation (No. 2015M570305), and the Heilongjiang Postdoctoral Fund (No.LBH-Z14179).

\section{REFERENCES}

Ackerson CJ, Jadzinsky PD, Kornberg RD. Thiolate ligands for synthesis of water-soluble gold clusters. J Am Chem Soc. 2005;127(18):6550-6551.

Araki T, Ogawara K, Suzuki H, Kawai R, Watanabe T, Ono $\mathrm{T}$, . Augmented EPR effect by photo-triggered tumor vascular treatment improved therapeutic efficacy of liposomal paclitaxel in mice bearing tumors with low permeable vasculature. J Control Release. 2015;200(28):106-114.

Balthasar S, Michaelis K, Dinauer N, Von Briesen H, Kreuter J, Langer K. Preparation and characterisation of antibody modified gelatin nanoparticles as drug carrier system for uptake in lymphocytes. Biomaterials. 2005;26(15):2723-2732.

Breunig M, Bauer S, Goepferich A. Polymers and nanoparticles: intelligent tools for intracellular targeting? Eur J Pharm Biopharm. 2008;68(1):112-128.

Chen Z, Tai Z, Gu F, Hu C, Zhu Q, Gao S. Aptamer-mediated delivery of docetaxel to prostate cancer through polymeric nanoparticles for enhancement of antitumor efficacy. Eur J Pharm Biopharm. 2016;107(10):130-141.

Cortes J, Saura C. Nanoparticle albumin-bound (nabTM)paclitaxel: improving efficacy and tolerability by targeted drug delivery in metastatic breast cancer. Eur J Cancer. 2010;Suppl $8(1): 1-10$.

Elzoghby AO. Gelatin-based nanoparticles as drug and gene delivery systems: reviewing three decades of research. J Control Release. 2013;172(3):1075-1091.

Elzoghby AO, Samy WM, Elgindy NA. Albumin-based nanoparticles as potential controlled release drug delivery systems. J Control Release. 2012;157(2):168-182.

Fattal E, Vauthier C, Aynie I, Nakada Y, Lambert G, Malvy C, et al. Biodegradable polyalkylcyanoacrylate nanoparticles for the delivery of oligonucleotides. J Control Release. 1998;53(13):137-143.
Fernandez-Urrusuno R, Calvo P, Remunan-Lopez C, Vila-Jato JL, Alonso MJ. Enhancement of nasal absorption of insulin using chitosan nanoparticles. Pharm Res. 1999;16(10):15761581.

Fonseca C, Simoes S, Gaspar R. Paclitaxel-loaded PLGA nanoparticles: preparation, physicochemical characterization and invitroanti-tumoral activity, J Control Release. 2002;83(2):273286.

Gan CW, Chien S, Feng SS. Nanomedicine: enhancement of chemotherapeutical efficacy of docetaxel by using a biodegradable nanoparticle formulation. Curr Pharm Des. 2010;16(21):2308-2320.

Harsha S. Pharmaceutical suspension containing both immediate/sustained release amoxicillin-loaded gelatin nanoparticles: preparation and in vitro characterization. Drug Des Dev Ther. 2013;26(7):1027-1033.

Hwang C. Overcoming docetaxel resistance in prostate cancer: a perspective review. Ther Adv Med Oncol. 2012;4(6):329-340.

Ibrahim NK, Desai N, Legha S, Soon-Shiong P, Theriault RL, Rivera E, et al. Phase I and pharmacokinetic study of ABI-007 a Cremophor-free, protein-stabilized, nanoparticle formulation of paclitaxel. Clin Cancer Res. 2002;8(5):1038-1044.

Jithan A, Madhavi K, Madhavi M, Prabhakar K. Preparation and characterization of albumin nanoparticles encapsulating curcumin intended for the treatment of breast cancer. Int J Pharm Invest. 2011;1(2):119-125.

Jun JY, Nguyen HH, Paik SYR, Chun HS, Kang BC, Ko S. Preparation of size-controlled bovine serum albumin (BSA) nanoparticles by a modified desolvation method. Food Chemistry. 2011;127(4):1892-1898.

Kratz F. Albumin as a drug carrier: design of prodrugs, drug conjugates and nanoparticles. J Control Release. 2008;132(3):171-183.

Kratz F. WITHDRAWN: a clinical update of using albumin as a drug vehicle - a commentary. J Control Release. 2014;190(3):331-336.

Lesch HP, Kaikkonen MU, Pikkarainen JT, Ylä-Herttuala S. Avidin-biotintechnology in targeted therapy. Expert Opin Drug Deliv. 2010;7(5):551-564. 
Li M, Lam JWY, Mahtab F, Chen S, Zhang W, Hong Y, et al. Biotin-decorated fluorescent silica nanoparticles with aggregation-induced emission characteristics: fabrication, cytotoxicity and bio-logical applications. J Mater Chem B. 2013;1(5):676-684.

Lindegren S, Frost SH. Pretargeted radioimmunotherapy with $\alpha$-particle emitting radionuclides. Curr Radiopharm. 2011;4(3):248-260.

Liu Z, Jiao Y, Wang Y, Zhou C, Zhang Z. Polysaccharides-based nanoparticles as drug delivery systems. Adv Drug Deliv Rev. 2008;60(15):1650-1662.

Liu Z, Liu D, Wang L, Zhang J, Zhang N. Docetaxel-loaded pluronic p123 polymeric micelles: in vitro and in vivo evaluation. Int J Mol Sci. 2011;12(3):1684-1696.

Mårtensson L, Nilsson R, Ohlsson T, Sjögren HO, Strand SE, Tennvall J. Improved tumor targeting and decreased normal tissue accumulation through extracorporeal affinity adsorption in a two-step pretargeting strategy. Clin Cancer Res. 2007; 13(18 Pt 2):5572s-5576s.

Marysael T, Bauwens M, Ni Y, Bormans G, Rozenski J, de Witte JP. Pretargeting of necrotic tumors with biotinylated hypericin using 123I-labeled avidin: evaluation of a two-step strategy. Invest New Drugs. 2012;30(6):2132-2140.

Mehta D, Bhattacharya J, Matthay MA, Malik AB. Integrated control of lung fluid balance. Am J Physiol Lung Cell Mol Physiol. 2004;287(6):1081-1090.

Mirzaie ZH, Irani S, Mirfakhraie Reza, Atyabi SM, Dinarvand M, Dinarvand R, et al. Docetaxel-Chitosan nanoparticles for breast cancer treatment: cell viability and gene expression study. Chem Biol Drug Des. 2016;88(6):850-858.

Moreno F, Cortijo M, Gonzalez-Jimenez J. The fluorescent probe prodan characterizes the warfarin binding site on human serum albumin. Photochem Photobiol Sci. 1999;9(1):8-15.

Musumeci T, Ventura CA, Giannone I, Ruozi B, Montenegro L, Pignatello R, et al. PLA/PLGA nanoparticles for sustained release of docetaxel. Int J Pharm. 2006;325(1-2):172-179.

Nateghian N, Goodarzi N, Amini M, Atyabi F, Khorramizadeh MR, Dinarvand R. Biotin/folate-decorated human serum albumin nanoparticles of docetaxel: comparison of chemically conjugated nanostructures and physically loaded nanoparticles for targeting of breast cancer. Chem Biol Drug Des. 2016;87(1):69-82.
Panyam J, Labhasetwar V. Dynamics of endocytosis and exocytosis of poly(D,L-Lactide-co-Glycolide) nanoparticles in vascular smooth muscle cells. Pharm Res. 2003;20(2):212220 .

Nichols JW, Bae YH. EPR: evidence and fallacy. J Control Release. 2014;190(28):451-464.

Patel M, Vadlapatla RK, Shah S, Mitra AK. Molecular expression and func-tional activity of sodium dependent multivitamin transporter in human prostatecancer cells. Int $\mathrm{J}$ Pharm. 2012;436(1-2):324-331.

Roney C, Kulkarni P, Arora V, Antich P, Bonte F, Wu A, et al. Targeted nanoparticles for drug delivery through the blood-brain barrier for Alzheimer's disease. J Control Release. 2005;108(23):193-214.

Russell-Jones G, McTavish K, McEwan J, Rice J, Nowotnik D. Vitamin-mediated targeting as a potential mechanism to increase drug uptake by tumours. J Inorg Biochem. 2004;98(10):16251633.

Sperling RA, Parak WJ. Surface modification, functionalization and bioconjugation of colloidal inorganic nanoparticles. Philos Trans R Soc. 2010;368(1915):1333-1383.

Stylianopoulos T. EPR-effect: utilizing size-dependent nanoparticle delivery to solid tumors. Ther Deliv. 2013;4(4):421423.

Uppal JK, Varshney R, Hazari PP, Chuttani K, Kaushik NK, Mishra AK. Biological evaluation of avidin-based tumor pretargeting with DOTA-Triazole-Biotin constructed via versatile $\mathrm{Cu}(\mathrm{I})$ catalyzed click chemistry. J Drug Target. 2011;19(6):418-426.

Urbanska K, Lanitis E, Poussin M, Lynn RC, Gavin BP, Kelderman S, et al. A universal strategy for adoptive immunotherapy of cancer through use of a novel T-cell antigen receptor. Cancer Res. 2012;72(7):1844-1852.

Vardhan H, Mittal P, Adena SK, Mishra B. Long-circulating polyhydroxybutyrate-co-hydroxyvalerate nanoparticles for tumor targeted docetaxel delivery: Formulation, optimization and in vitro characterization. Eur J Pharm Sci. 2017;99(1):85-94.

$\mathrm{Xu}$ CL, Yan Ping, Wang Lin, An GC. The synthesis and application of biotin N- hydroxysuccinimide ester. Chem Intermediate. 2007;1:15-16. 
Xu Z, Chen L, Gu W, Gao Y, Lin L, Zhang Z, et al. The performance of docetaxel-loaded solid lipid nanoparticles targeted to hepatocellular carcinoma. Biomaterials. 2009;30(2):226-232.

Yallapu MM, Gupta BK, Jaggi M, Chauhan SC. Fabrication of curcumin encapsulated PLGA nanoparticles for improved therapeutic effects in metastatic cancer cells. J Colloid Interface Sci. 2010;351(1):19-29.

Ye Y, Zhang T, Li W, Sun H, Lu D, Wu B, et al.. Glucosebased mesoporous carbon nanospheres as functional carriers for oral delivery of amphiphobic raloxifene: insights into the bioavailability enhancement and lymphatic transport. Pharm Res. 2016;33(3):792-803.
Yu XY, Yang Y, Zou X, Tao HW, Ling YL, Yao Q, et al. Study on the interaction between novel spiro pyrrolidine and bovine serum albumin by spectroscopic techniques. Spectrochim Acta. A: Mol Biomol Spectrosc. 2012;94(8):23-29.

Zhang YZ, Zhou B, Liu YX, Zhou CX, Ding XL, Liu Y. Fluorescence study on the interaction of bovine serum albumin with p-aminoazobenzene. J Fluoresc. 2008;18(1):109-118.

Zhao P, Astruc D. Docetaxel nanotechnology in anticancer therapy. Chem Med Chem. 2012;7(6):952-972.

Zuo TT, Guan YY, Chang ML, Zhang F, Lu SS, Wei T, et al. RGD(Arg-Gly-Asp) internalized docetaxel-loaded pH sensitive liposomes: Preparation, characterization and antitumor efficacy in vivo and in vitro. Colloid Surfaces B. 2016;147:90-99.

Received for publication on $22^{\text {th }}$ May 2017 Accepted for publication on $23^{\text {th }}$ November 2017 